\section{New variants in beta globin gene among the Palestinian refugees with sickle cell disease in Lebanon} Esraa Y. Moussa, BSc, MSc, Noura M. Yassine, $M S c, P h D$,
Jamilah M. Borjac, MSc, PhD.

\begin{abstract}
Objectives: To examine the association between beta-globin sequence variations and phenotypes of sickle-cell disease (SCD) complications among Palestinian refugees in Lebanon correlating them with chromatographic readings and co-inheritance with $\beta$-thalassemia traits.
\end{abstract}

Methods: This cross-sectional study included 47 Palestinian refugees aged 4 to 54 living in different regions in Lebanon during the year 2015. Participant filled a well-designed questionnaire. Deoxyribonucleic acid (DNA) was purified from the blood collected from all participants, followed by polymerase chain reaction (PCR) amplification of exon 1, exon 2, and IVS 1 of hemoglobin beta. Multiple sequence alignment for comparative analysis was performed against normal hemoglobin sequences.

Results: In addition to well-known SCD mutations, rare beta globin variations were identified. Participants with these variations have phenotypic thalassemia despite the absence of known $\beta$-thalassemia mutations.

Conclusion: The genetic variation seen among our study population is correlated with reduced beta globin transcription, and phenotypic $\beta$-thalassemia complications among SCD patients under study.

Saudi Med J 2018; Vol. 39 (12): 1253-1258 doi: 10.15537/smj.2018.12.23113

$\mathrm{H}$ emoglobinopathies refer to hemoglobin $(\mathrm{Hb})$ disorders, mainly resulting from genetic defects. Hemoglobinopathies have 2 primary pathological mechanisms. Genetic defects may alter the structure of the $\mathrm{Hb}$ molecule, as in sickle-cell disease (SCD) which is most commonly due to hemoglobin $\mathrm{S}(\mathrm{HbS})$ or hemoglobin $\mathrm{C}$ disease (HbC). Alternatively, genetic defects may diminish the biosynthesis of one of the 2 subunits of the $\mathrm{Hb}$ molecule, as in the 2 major forms of thalassemia, $\alpha$ - and $\beta$-. Hereditary persistence of fetal hemoglobin $(\mathrm{HbF})$ and acquired conditions like methemoglobinemia are alternative forms of hemoglobinopathy. ${ }^{1} \mathrm{HbS}$ is caused by a single missense variation in the beta-globin gene leading to a glutamic-to-valine substitution at the sixth residue of beta-globin polypeptide. ${ }^{2}$ When 2 copies of $\mathrm{HbS}$ are inherited in an autosomal recessive fashion it causes sickle cell anemia, the most common and severe variant of SCD. ${ }^{3}$

Normal adult oxy- and deoxyhemoglobin molecules are water soluble. However, $\mathrm{HbS}$ polymerizes upon deoxygenation due to the hydrophobic interaction that valine 6 forms with other hemoglobin chains. Polymerized HbS aggregates in long twisted bundles, changing the shape of RBCs from a biconcave disc to an irregular "sickle". This change in shape exposes intracellular protein epitopes and lipids on the surface of the RBCs. As RBCs circulate, undergoing repeated deoxygenation the repeated polymerization and depolymerization of the $\mathrm{HbS}$ damages the erythrocytes leading to obstruction of the blood vessels, disruption of endothelial cell function, eventual tissue hypoxia and other clinical complications. ${ }^{4}$ The red blood cells lifespan shortens and their lysis releases cell-free hemoglobin $(\mathrm{Hb})$ into the circulation leading to clinical manifestations of anemia.

Different variants of beta-globin genes produce diverse clinical pathologies, depending on the percentage and type of variant $\mathrm{Hb}^{5}$ Clinical manifestations of SCD differ among different populations. It may also coexist with thalassemia, another highly prevalent hemoglobinopathy. ${ }^{6}$ Sickle-cell disease can have different severities, the most severe variant is due HbSS. However, when the $\beta^{\text {s }}$ gene combines with $\beta$-thalassemia gene, the severity of the disease depends on the severity of the inherited $\beta$-thalassemia mutation. Furthermore, different types of $\beta$-thalassemia can combine with SCD affecting the clinical phenotype.

Gel electrophoresis is commonly used to diagnose sickle-cell anemia by observing the migration of $\mathrm{HbS}$. Other sickling genotypes are analyzed by sequencing specific targeted DNA. Early diagnosis of SCD is also possible by sequencing fetal DNA obtained by chorionic villus sampling. ${ }^{7}$ There are diverse therapeutic strategies to treat SCD. Stimulation of $\mathrm{HbF}$ production, with drugs such as hydroxyurea, ${ }^{8}$ butyrate, ${ }^{9}$ 5-aza-2deoxycytidine, ${ }^{10}$ has been shown to ameliorate the clinical severity of SCD by interfering with the polymerization of deoxygenated $\mathrm{HbS}$ in vitro. ${ }^{11}$ However, bone marrow transplantation is considered the only curative therapy for SCD. ${ }^{12}$ As discussed a number of beta-globin gene variations has been identified. Although many studies have associated beta-globin gene variations with SCD complications, none have studied the population of Palestinian refugees in Lebanon. This study aimed to search for novel mutations in beta-globin chain in 
Palestinian refugees in Lebanon with reported history of SCD, and correlate these variations to related phenotypes (Hb variants, level, and SCD complications) with high performance liquid chromatography (HPLC) findings of $\mathrm{Hb}$ electrophoresis.

Methods. After obtaining approval from the Research Ethics Board of Balsam Red Crescent Hospital, this cross-sectional study enrolled 47 Palestinian patients (36 with SCD and 11 healthy participants). Participants (24 male and 23 female) were aged 4 to 54 years and are living in various geographic regions of Lebanon. Participants were recruited from Red Crescent Hospital, Lebanon in 2015. After participants or their guardians signed consent forms, blood samples were collected in ethylendiamine-tetraacetic acid (EDTA) tubes, and relevant clinical data including age, medical history, marriage consanguinity, treatment, and clinical complications were collected using a well-designed questionnaire and from the hospital records. Hemoglobin electrophoresis results were obtained from different clinical centers and from United Nations Relief and Works Agency (UNRWA) for Palestine refugees in the near East. The study was performed according to the guidelines of the Institutional Review Board at Beirut respecting all principles of Helsinki Declaration.

DNA extraction. Genomic DNA was isolated from whole blood of participants using QIAamp DNA Mini Kit (Qiagen, Germany) according to manufacturer recommendations. Absorbance of DNA was measured at 260 and $280 \mathrm{~nm}$ using a spectrophotometer from Thermo Scientific, USA to determine its concentration and its purity. Its integrity was confirmed by agarose gel electrophoresis.

Primer design and polymerase chain reaction (PCR). Deoxyribonucleic acid primers were synthesized by Thermo Scientific (USA). Primers were designed to amplify region that extends from the 5'non-coding sequence (-140 bp from transcription start site) to the second intron including exons 1 and 2 yielding a 725 bp product including both primers.

Polymerase chain reaction was performed in a DNA thermal cycler (Bio-Rad, USA) using 5' GCC AAG GAC AGG TAC GGC TGT C3' as a forward primer and 5'CTG TAC CCT GTT ACT TAT CCC CT3'as a reverse primer. Reaction was carried out in a total

Disclosure. Authors have no conflict of interests, and the work was not supported or funded by any drug company. volume of $50 \mu \mathrm{l}$ containing $5 \mu \mathrm{l}$ template DNA (10 $\mathrm{ng}), 2.5 \mu \mathrm{l}$ of forward and reverse primers $(5 \mu \mathrm{M}), 25$ $\mu \mathrm{l}$ PCR of $2 \mathrm{x}$ Master Mixture (Thermo Scientific, USA) and nuclease free water to make up to volume.

Polymerase chain reaction cycle included the following steps:1) a denaturation step at $95^{\circ} \mathrm{C}$ for 3 minutes; 2) 30 cycles each consisting of 30 seconds at $95^{\circ} \mathrm{C}, 30$ seconds at $57^{\circ} \mathrm{C}$, and 60 seconds at $72^{\circ} \mathrm{C}$; 3) 10 minutes at $72^{\circ} \mathrm{C}$. The size of the obtained PCR products was confirmed by agarose electrophoresis and visualized using UV transillumination (Chemi Doc-It, UVP, USA).

Sequencing PCR products. Polymerase chain reaction products obtained from the 47 participants were purified using illustra ${ }^{\mathrm{TM}}$ GFX PCR DNA and Gel Band Purification Kit (GE Healthcare, Buckinghamshire, UK). The resulting products were sequenced using the BigDye ${ }^{\oplus}$ Terminator v1.1 Cycle Sequencing Kit (ThermoFisher Scientific, Waltham, MA, USA) under standard conditions. The labeled products were subjected to electrophoresis on an ABI 3500 Genetic Analyzer sequencing system (ThermoFisher Scientific, Waltham, MA, USA). Electropherograms were analyzed using Sequence Analysis Software version 5.4 (ThermoFisher Scientific, Waltham, MA, USA) and compared to reference sequences using ChromasPro version 1.7.7 (Technelysium, Queensland, Australia).

Statistical analysis. Data was analyzed using the Statistical Package for Social Sciences (SPSS) software, version 23 (SPSS, Inc, Chicago, IL, USA). To describe the categorical variables, frequencies and percentages were calculated. Association analysis was carried out using Pearson's Chi-square and 2-tailed Fisher's Exact test. Descriptive statistics (mean \pm standard deviation) and a 2-sample t-test was used for continuous data to compare means between the SS and ST groups respectively. The level of significance was set at $p<0.05$ for all tests.

Results. The participants in this study included 23 Palestinian females and 24 Palestinian males aged 4 to 54 years (mean of 25.4 years \pm 13.3 ) from various geographic areas in Lebanon. The majority of the participants were descended from the Arab El Ghor lineage that have high rate of consanguineous marriages. Patient history was obtained through a well-designed questionnaire including gender, consanguinity, treatment, complications, diagnosis, and treating hospitals. Hemoglobin electrophoresis results were obtained from different clinical centers in Lebanon and from UNRWA. 
Table 1 - Hemoglobin variants observed among all study participants.

\begin{tabular}{lccrrr}
\hline HPLC diagnosis & $\begin{array}{c}\text { Sample count } \\
\mathbf{n}(\%)\end{array}$ & \% HbA2 & \% HbF & \% HbS & $\% \mathrm{HbA}$ \\
\hline HBSS & $13(27.7)$ & $2.7 \pm 0.7$ & $1.9 \pm 2.5$ & $36.2 \pm 4.2$ & $59.06 \pm 6.2$ \\
HBSA & $18(38.3)$ & $3.64 \pm 1.06$ & $19.09 \pm 6.4$ & $77.80 \pm 7.2$ & 0 \\
HbS/ß-thal (mild) & $3(6.4)$ & $4.8 \pm 1.3$ & $6.1 \pm 3.4$ & $70.6 \pm 0.6$ & $18.4 \pm 2.9$ \\
HbS/ß-thal (moderate) & $2(4.2)$ & $4.4 \pm 1.48$ & $20.85 \pm 8.3$ & $65.85 \pm 14$ & $8.85 \pm 4.3$ \\
Healthy & $11(23.4)$ & $2.1 \pm 0.5$ & $0.6 \pm 0.7$ & 0 & $97.4 \pm 0.4$ \\
\hline
\end{tabular}

Values are represented as mean \pm SD. Normal values: $\mathrm{HbF}<1 \%, \mathrm{HbA} 2-2 \%-3 \%$.

HPLC - high performance liquid chromatography, HbA2 - hemoglobin A2, HbF - fetal hemoglobin, HbS - hemoglobin S, $\mathrm{HbA}$ - hemoglobin A

Analysis of hemoglobin types. Participants were classified into 5 different groups based on their $\mathrm{Hb}$ profiles as summarized in Table 1.

Sequencing data. The distribution of HBB variations obtained from sequencing the amplified PCR products obtained from the 36 patients in this study is shown in Table 2 .

Table 3 shows the genotype of each participant along with identified variations and treatment taken if any.

Association studies between DNA variations in Beta-globin gene and consanguinity. In order to study if there is association between consanguinity and SCD
Table 2 - Distribution of HBB variations among the 36 patients.

\begin{tabular}{lrr}
\hline HBB variations & $\begin{array}{c}\text { Count }(\mathbf{n}=36) \\
\mathbf{n}(\%)\end{array}$ \\
\hline cd6 and other variations & 18 & $(50.0)$ \\
Heterozygosity $\left(\beta^{\sigma} \beta^{\mathrm{a}}\right)$ & 18 & $(50.0)$ \\
Homozygosity $\left(\beta^{\sigma} \beta^{s}\right)$ & 3 & $(8.3)$ \\
$-88-\mathrm{C}$ & 2 & $(5.6)$ \\
$-73 \mathrm{~A}>\mathrm{G}$ & 7 & $(19.4)$ \\
$(-74-\mathrm{A})$ along with $(-75 \mathrm{C}>\mathrm{A})$ & 2 & $(5.6)$ \\
IVS1.108T>C & 6 & $(16.7)$ \\
IVS1.110G>A & HBB - Normal $\beta$-globin gene \\
\hline \multicolumn{2}{c}{} \\
\hline
\end{tabular}

Table 3 - Normal $\beta$-globin gene variations and treatment among patients in the study.

\begin{tabular}{|c|c|c|}
\hline Groups of participants & $\begin{array}{l}\text { Percentage of variation among different } \\
\text { groups }\end{array}$ & Treatment $(\%)$ \\
\hline $\operatorname{HbSS}(\mathrm{n}=18)$ & $\begin{array}{rr}\text { IVS1.110G }>A & (16.7) \\
-74-A,-75 C>A & (27.8) \\
-88-C & (11.1) \\
-73 A>G & (5.6)\end{array}$ & $\begin{array}{l}\text { Hydroxyurea + folic acid }(100) \\
\text { Transfusion+ddesferal }(11.1)\end{array}$ \\
\hline $\operatorname{HbAS}(\mathrm{n}=13)$ & IVS1.108T>C & Folic acid (38.5) \\
\hline HbS/ $\beta$-thal (Moderate) $(\mathrm{n}=2)$ & $\begin{array}{rr}\text { IVS1.110G }>A & (100) \\
-73 A>G & (50.0) \\
-88-C & (50.0) \\
-74-A,-75 C>A & (50.0)\end{array}$ & $\begin{array}{r}\text { Hydroxyurea+Folic acid }(50.0) \\
\text { Folic acid }(50.0)\end{array}$ \\
\hline $\mathrm{HbS} / \beta$-thal $(\mathrm{Mild})(\mathrm{n}=3)$ & $\begin{array}{ll}\text { IVS1.110G }>A & (33.3) \\
\text { IVS1.108T>C } & (33.3) \\
-74-A,-75 C>A & (33.3)\end{array}$ & Folic acid (66.7) \\
\hline
\end{tabular}

Table 4 - Association between consanguinity and codon 6 of HBB gene variants.

\begin{tabular}{lcccc}
\hline Consanguinity & $\begin{array}{c}\text { Codon 6 (GAG/GTG) } \\
\text { carrier }\end{array}$ & $\begin{array}{c}\text { Codon 6 (GAG/GAG) } \\
\text { normal }\end{array}$ & $\begin{array}{c}\text { Codon 6 (GTG/GTG) } \\
\text { affected }\end{array}$ & Total \\
\hline Yes & $9(50.0)$ & $5(35.7)$ & $10(55.5)$ & $24(48.0)$ \\
No & $9(50.0)$ & $9(64.2)$ & $8(44.4)$ & $26(52.0)$ \\
Total & $18(100)$ & $14(100)$ & $18(100)$ & $50(100)$ \\
\hline \multicolumn{5}{c}{ Values are presented as number and percentage (\%). HBB - normal $\beta$-globin gene. } \\
& No significant association between consanguinity and HB variants, $p=0.52$ \\
\hline
\end{tabular}


Table 5 - Associations with different observed clinical complications.

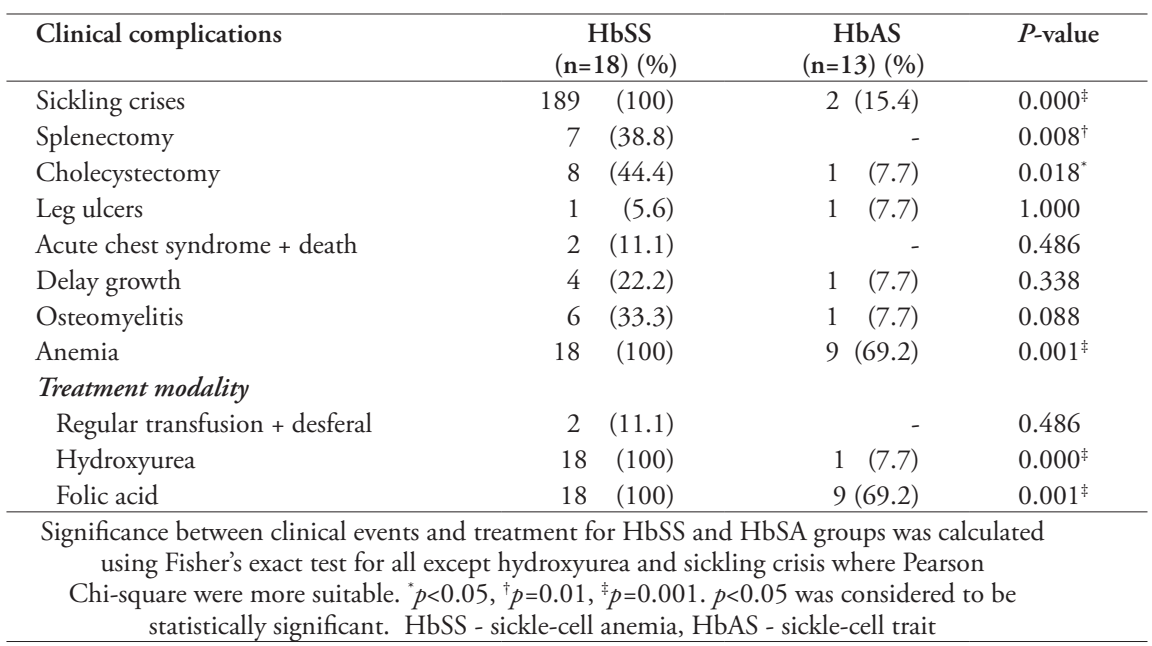

Table 6 - Association between clinical complications and different observed variations.

\begin{tabular}{|c|c|c|c|c|}
\hline Complications & $\begin{array}{l}\text { Patients with } \\
\text { IVS1.110G }>A \\
(n=6)\end{array}$ & $P$-value & $\begin{array}{l}\text { Patients with }(-74-A)+ \\
\quad(-75 C>M)(n=7)\end{array}$ & $P$-value \\
\hline Sickling crises & $\begin{array}{ll}5 & (83.3)\end{array}$ & 0.240 & $5 \quad(71.4)$ & 0.454 \\
\hline Splenectomy & $1 \quad(16.7)$ & 1.000 & $3 \quad(42.9)$ & 0.100 \\
\hline Cholecystectomy & $2 \quad(33.3)$ & 0.623 & $3 \quad(42.9)$ & 0.334 \\
\hline Delay growth & $1 \quad(16.7)$ & 0.176 & $1 \quad(14.2)$ & 1.000 \\
\hline Osteomyelitis & $2 \quad(33.3)$ & 0.310 & $2 \quad(28.6)$ & 0.100 \\
\hline Anemia & $6 \quad(100)$ & 0.117 & $7 \quad(100)$ & $0.006^{\dagger}$ \\
\hline
\end{tabular}

variation, Chi-square test $(\mathrm{df}=2)$ was used to calculate $p$-value to test for significance. No statistical significance was obtained $(p=0.52)$ as shown in Table 4.

Association between beta-globin variations and SCD complications. Table 5 and Table 6 show the associations between the $\mathrm{HBB}$ variations and different observed clinical complications and treatment modalities. The association between sickling crises, anemia, intake of folate and hydroxyurea were considered to be statistically significant for SS and ST patients $(p<0.05)$. However, there was no association seen at the level of regular transfusion and desferal uptake $(p>0.05)$ nor for the additional SCD complications. Furthermore, there was no significant association between the clinical events and the observed variations except for anemia.

Discussion. Sickle-cell disease and thalassemia are considered the most inherited hemoglobinopathies among Mediterranean populations. The aim of this study was to screen parts of the beta-globin gene to examine the association between mutations in beta-globin and related phenotypes such as SCD complications in Palestinian refugees in Lebanon. We also determined whether these mutations are associated with the HPLC diagnosis of SCD.

By comparing our observed variations to other populations, we notice that our Palestinian participants also possess the known $\beta$-thalassemia mutation IVS1.110G $>\mathrm{A}$ in a heterozygous form. This mutation creates a new alternative acceptor AG, 19 bp $5^{\prime}$ to the normal acceptor AG of IVS1 which is used in $80 \%$ to $90 \%$ of the transcript. ${ }^{13}$ As for the $-74-\mathrm{A}$ variation, this change was also observed a mong all Lebanese participants who were involved in a sickle cell research project performed at Beirut Arab University. This variation is not reported in gene bank as well. Furthermore, the variations seen in a heterozygous form, $-73 \mathrm{~A}>\mathrm{G}$, -88-C, IVS1.108T $>C$, $-75 \mathrm{C}>\mathrm{A}$, were observed among the Palestinian participants in this study. 
Based on $\mathrm{Hb}$ electrophoresis diagnosis of the 47 participants, 18 participants $(38.3 \%)$ had HbSS, 13 participants $(27.7 \%)$ had HbAS, 3 (6.4\%) had $\mathrm{HbS} / \beta$-thalassemia (mild), 2(4.2\%) had $\mathrm{HbS} / \beta$-thalassemia (moderate), and 11 (23.4\%) had normal HBAA. After associating the sequencing results of the amplified DNA with $\mathrm{Hb}$ types and the collected data from the participants, we can conclude that $60 \%$ of the participants with the thalassemia phenotype were heterozygous with IVS1.110G $>A, 40 \%$ had the $-74-\mathrm{A},-75 \mathrm{C}>\mathrm{A}$ variation, $20 \%$ had the $-88-\mathrm{C}$ variation, $20 \%$ had the $-73 \mathrm{~A}>\mathrm{G}$ variation, and $20 \%$ had the IVS1.108T $>C$ variation. However, none of the participants with $\mathrm{HbSA}$ had these variations except for one participant with $-74-\mathrm{A},-75 \mathrm{C}>\mathrm{A}$. This may suggest that our variations may affect the level of transcribed beta-globin gene and the phenotypic complications among SCD patients.

All participants with HbSS were under hydoxyurea and folate treatment regardless whether they possessed additional variations besides the codon 6 variation or not. This uptake may explain the high level of $\mathrm{HbF}$ (19\%) observed in this group.

The IVS1.110G>A mutation is well established and documented to be related to thalassemia among diverse populations. The different severity observed among the participants may be related to the additional variations in beta-globin gene seen. There may be an association between variations seen at the level of beta-globin gene and the observed phenotypic $\beta$-thalassemia that is leading to different severities and complications. Hence, those with further beta-globin variations suffer from $\beta^{+}$-thalassemia with different severity (Table 3 ).

Many studies have examined the association of SCD with thalassemia. In a 2014 study carried out in Cameroonian patients showed that $36 \%$ of SCD patients have $\alpha$-thalassemia. ${ }^{13}$ In a 2013 study carried out on Yemeni patients concluded that alpha thalassemia is at least one independent variable that may modify the hematological and clinical course of SCD. ${ }^{14,15}$ Finally, coinheritance of $\alpha$-thalassemia and SCD has been associated with a reduced sickled $\mathrm{Hb}$ concentration in erythrocytes, leading to reduced $\mathrm{Hb} \mathrm{S}$ polymerization, lowered sickling and rate of hemolysis. This study did not examine the $\alpha$-globin gene for an association between our study phenotype and $\alpha$-globin inheritance but it is of interest in further research as there was interesting reduction in $\mathrm{HbS}$ level in our patients.

The statistically significant high level of $\mathrm{HbF}$ seen in the HbSS participants $(19.09 \pm 6.4)$ could be due either to the presence of a factor that is causing up-regulation of $\mathrm{HbF}$, or due to hydroxyurea uptake that normally increases erythroid differentiation in the bone marrow. ${ }^{8,11}$ Furthermore, the deletion of both $\mathrm{A}$ and $\mathrm{C}$ nucleotide and substitution of $\mathrm{C}$ by $\mathrm{A}(-75 \mathrm{C}>\mathrm{A})$ in the basal promoter may alter the expression of $\mathrm{HBB}$ gene. Since we observed an associated decrease in the level of HbS, we may suggest that this deletion may affect transcription rate by modulating the binding of RNA polymerase and any of the transcription factors.

Using Fisher test, comparing \% $\mathrm{Hb} \mathrm{F}$ in the form of Mean \pm SD among HbSS and HbSA groups, we find that for HbSS participants it is $19.09 \pm 6.4$ which is significantly greater than that of HbAS groups $1.9 \pm 2.5$ $(p=0.000)$. However, no significant difference was seen among Lebanese HbSS $(15.79 \pm 13.25)$ and HbAS $(12.81 \pm 11.73)$ groups. ${ }^{16}$ Therefore, a bigger sample size should use in future research to establish a firm conclusion.

Finally, it is worth noting that SCD is understudied in this population. No previous reports have examined the prevalence of SCD in Palestinian refugees in Lebanon. The data in this study were collected data from camps, different clinical centers and from UNRWA. The number of observed cases in the different clinical centers was 335 patients. The number of Palestinians refugees living camps in Lebanon is approximately 450,000 . Therefore, the prevalence of SCD patients in the Palestinians refugees in Lebanon is $0.0744 \%$. The prevalence of SCD in Al Borj Camp in the south of Lebanon is $1.1 \%$. This camp comprises 1700 inhabitants where 189 patients have SCD. Further research would benefit this population which is likely to be underserved due to their refugee status.

Study limitation. Having a specific disease is a sensitive issue among Arabs in general. This limited study participation and by extension the significance of our results.

In conclusion, new variants in beta globin gene are identified in the Palestinina Refugees living in Lebanon that may be correlated with reduced beta globin transcription, and phenotypic $\beta$-thalassemia seen among the participants of this study.

Acknowledgement. The authors would like to acknowledge Balsam Hospital in Lebanon for inviting participants in this study to attend a lecture about sickle cell diseases and in assisting in blood sampling. A special thank to the Research medics for editing this manuscript.

Received 11th June 2018. Accepted 17th September 2018.

From the Department of Biological Sciences (Moussa, Borjac), and Department of Mathematics and Computer Science (Yassine), Beirut Arab University, Beirut, Lebanon. 
Address correspondence and reprints request to: Dr. Jamilah M. Borjac, Department of Biological Sciences, Faculty of Science, Beirut Arab University, Beirut, Lebanon.E-mail: j.borjac@bau.edu.lb

ORCID ID: orcid.org/0000-0002-7722-5617

\section{References}

1. Kohne E. Hemoglobinopathies: clinical manifestations, diagnosis, and treatment. Dtsch Arztebl Int 2011; 108: 532540.

2. Bunn HF, Forget BG. Hemoglobin: Molecular, genetic and clinical aspects. Philadelphia (PA): W. B. Saunders Company; 1986. p. 690.

3. Ashley-Koch A, Yang Q, Olney RS. Sickle hemoglobin (Hb S) allele and sickle cell disease: a HuGE review. American Journal of Epidemiology 2000; 151: 839-845.

4. Diez-Silva M, Dao M, Han J, Lim CT, Suresh S. Shape and biomechanical characteristics of human red blood cells in health and disease. MRS Bull 2010; 35: 382-388.

5. Thom CS, Dickson CF, Gell DA, Weiss MJ. Hemoglobin variants: biochemical properties and clinical correlates. Cold Spring Harb Perspect Med 2013; 3: a011858.

6. El-Hazmi MAF, Al-Hazmi AM, Warsy AS. Sickle cell disease in Middle East Arab countries. Indian J Med Res 2011; 134: 597-610.

7. Cheung MC, Goldberg JD, Kan YW. Prenatal diagnosis of sickle cell anaemia and thalassaemia by analysis of fetal cells in maternal blood. Nat Genet 1996; 14: 264-268.

8. Charache S, Dover GJ, Moore RD, Eckert S, Ballas SK, Koshy $\mathrm{M}$, et al. Hydroxyurea: effects on hemoglobin $\mathrm{F}$ production in patients with sickle cell anemia. Blood 1992; 79: 2555-2565.
9. Constantoulakis P, Knitter G, Stamatoyannopoulos G. On the induction of fetal hemoglobin by butyrates: in vivo and in vitro studies with sodium butyrate and comparison of combination treatments with 5-AzaC and AraC. Blood 1989; 74: 1963-1971.

10. Saunthararajah Y, Hillery CA, Lavelle D, Molokie R, Dorn L, Bressler L, et al. Effects of 5-aza-2'-deoxycytidine on fetal hemoglobin levels, red cell adhesion, and hematopoietic differentiation in patients with sickle cell disease. Blood 2003; 102: 3865-3870

11. Little JA, McGowan VR, Kato GJ, Partovi KS, Feld JJ, Maric I, et al. Combination erythropoietin-hydroxyurea therapy in sickle cell disease: experience from the National Institutes of Health and a literature review. Haematologica 2006; 91: 1076-1083.

12. Bolaños-Meade J, Brodsky RA. Blood and marrow transplantation for sickle cell disease: overcoming barriers to success. Curr Opin Oncol 2009; 21: 158-161.

13. Rumaney MB, Ngo Bitoungui VJ, Vorster AA, Ramesar $\mathrm{R}$, Kengne AP, Ngogang J, et al. The co-inheritance of alpha-thalassemia and sickle cell anemia is associated with better hematological indices and lower consultations rate in Cameroonian patients and could improve their survival. PLoS One 2014; 9: e100516.

14. El-Hazmi MA, Warsy AS. Pattern for alpha-thalassaemia in Yemeni sickle-cell-disease patients. East Mediterr Health J 1999; 5: 1159-1164.

15. Al-Ghazaly J, Al-Dubai W, Abdullah M, Al-Mahagri A, $\mathrm{Al}-\mathrm{Gharasi} \mathrm{L}$. Characteristics of sickle cell anemia in Yemen. Hemoglobin 2013; 37: 1-15.

16. Inati A, Jradi O, Tarabay H, Moallem H, Rachkidi Y, El Accaoui $\mathrm{R}$, et al. Sickle cell disease: the Lebanese experience. Int J Lab Hematol 2007; 29: 399-408. 